\title{
Aega komai, a new species of marine isopod crustacean (Aegidae: Flabellifera) from Japan
}

Niel L. Bruce

\begin{abstract}
Aega komai sp. nov. from Japanese waters, is described and figured from the single known specimen. Brief comments are given on the relationship of Aega komai sp. nov. to other species of the genus. The species is characterised by the plate-like expansion of antennule articles 1 and 2 , the flattened and expanded antenna article 5 , short, truncate and deeply serrate pleotelson, together with deeply serrate uropods, and the presence of a conspicuously large spine of pereopod 3 only.
\end{abstract}

\section{Introduction}

Knowledge of the Japanese marine isopod fauna, and that of the Aegidae in particular, results from three principal periods of activity. Contributions to knowledge of the Aegidae early this century are those of Thielemann (1910), and Richardson (1898, 1904, 1909), and much later, among the abundant contributions of Numomura (1981a, b, 1988, 1993). Also pertinent to this region is the monograph of Kussakin (1979). Currently there exists no guide to the isopods of Japan, nor is there a major review of the Aegidae of the region. The discovery of a new species of Aega, given the current state of knowledge, is therefore not altogether unusual.

The single holotypic specimen is, at the request of Dr. Tomoyuki Komai, deposited at the Zoological Museum, University of Copenhagen, Denmark (ZMUC). Abbreviations used: BL - body length; PMS - plumose marginal setae; PS - plumose setae.

\section{Taxonomy}

Family AEGIDAE White, 1850

Genus Aega Leach, 1815

Brusca (1983) and Kensley \& Schotte (1989) have given diagnoses to the genus, and generic level characters have been omitted from the description, and are to be assumed. Brusca (1983) erected two subgenera, the nominate subgenus and Ramphion. The species described here conforms to neither diagnosis, and is therefore not placed into either of the subgenera, although it belongs with those species placed in Aega (Aega) by having antennule articles 1 and 2 both flattened and expanded, the terminal article of the maxillipedal palp with recurved (hooked) spines and a clear rostral point.

Aega komai sp. nov.

Figs. 1-4

Material examined. - Holotype: $\delta$ (20.5 mm), off Chosi, Honshu, Central Japan, c. $14^{\circ} 50^{\prime} \mathrm{E}, 35^{\circ} 20^{\prime} \mathrm{N}, 18$ January 1995 , on the mantle of the squid Loligo bleekeri Keferstein, coll. T. Komai (ZMUC CRU1981).

Other material. - Specimens of Aega angustata Whitelegge, 1901 were examined for comparison to the Japanese material: $q$ ( $28 \mathrm{~mm}$, non-ovig), off Lakes Entrance, Victoria, Australia (AM P12146). ९ (22 mm, non-ovig), East of Sydney, New South Wales, Australia, Dec. 1980, coll. FRV Kapala (AM P43975). 


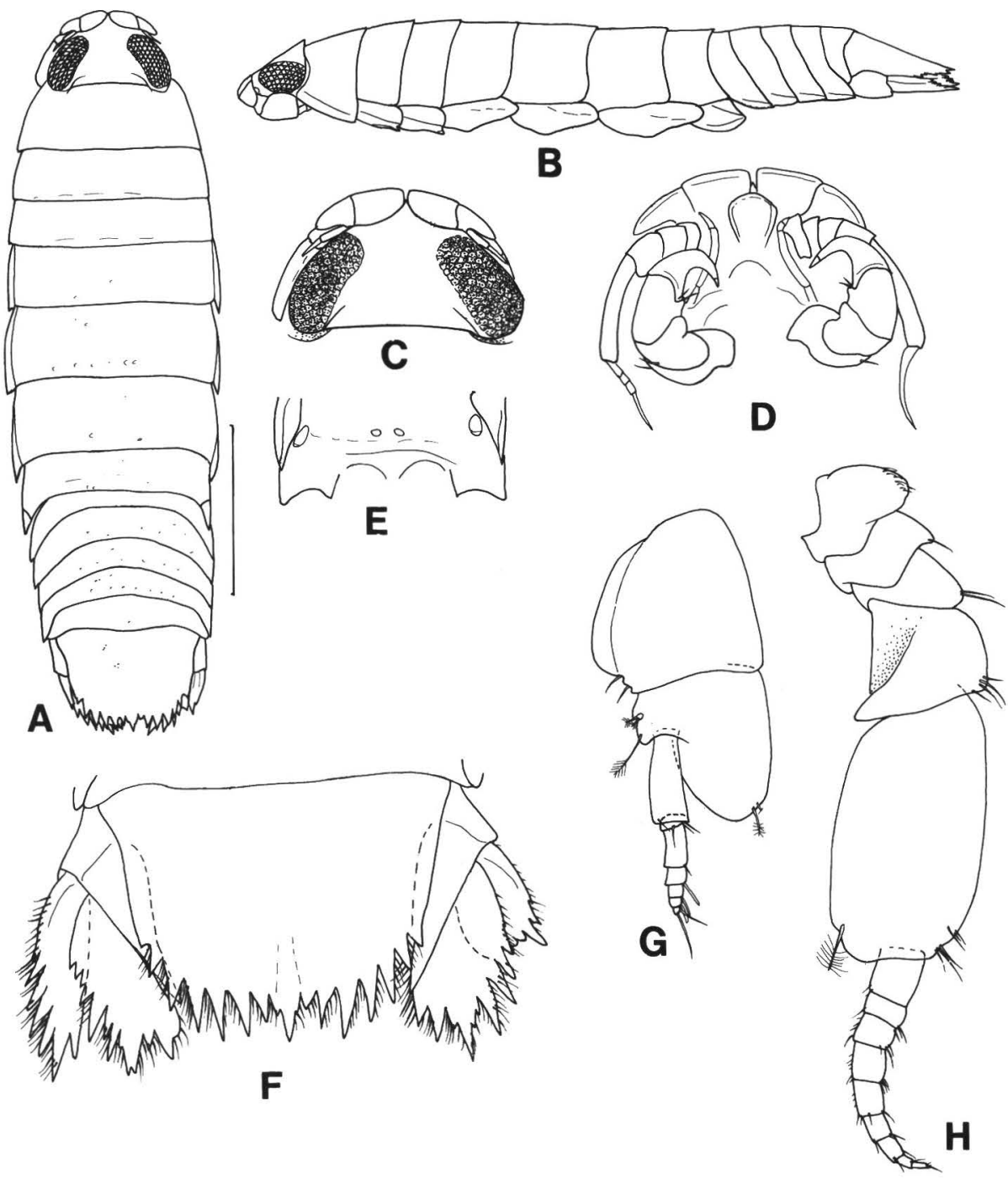

Fig. 1. Aega komai sp. nov., holotype. A, dorsal view; B, lateral view; C, cephalon, dorsal view; D, frons; E, sternite 7, showing penial papillae; F, pleotelson and uropods; G, antennule; $H$, antenna. Scale $5.0 \mathrm{~mm}$.

Etymology. - The species is named in honour of the collector, Dr. Tomoyuki Komai, and recognises his contribution to the knowledge of Japanese decapod crustaceans.

Description of male holotype. - Body about 3.3 times as long as greatest width, dorsal surfaces smooth, unornamented; lateral margins subparallel; maximum width at pereonite 5. Cephalon with prominent median rostral process, in ventral view extending slightly anterior to frontal lamina; eyes large, separate, occupying $48 \%$ width of cephalon in dorsal view, each with about 8 ocelli across, 15 lengthwise. Pereonites 1 and 6 longest, subequal in length to cephalon; pereonite 


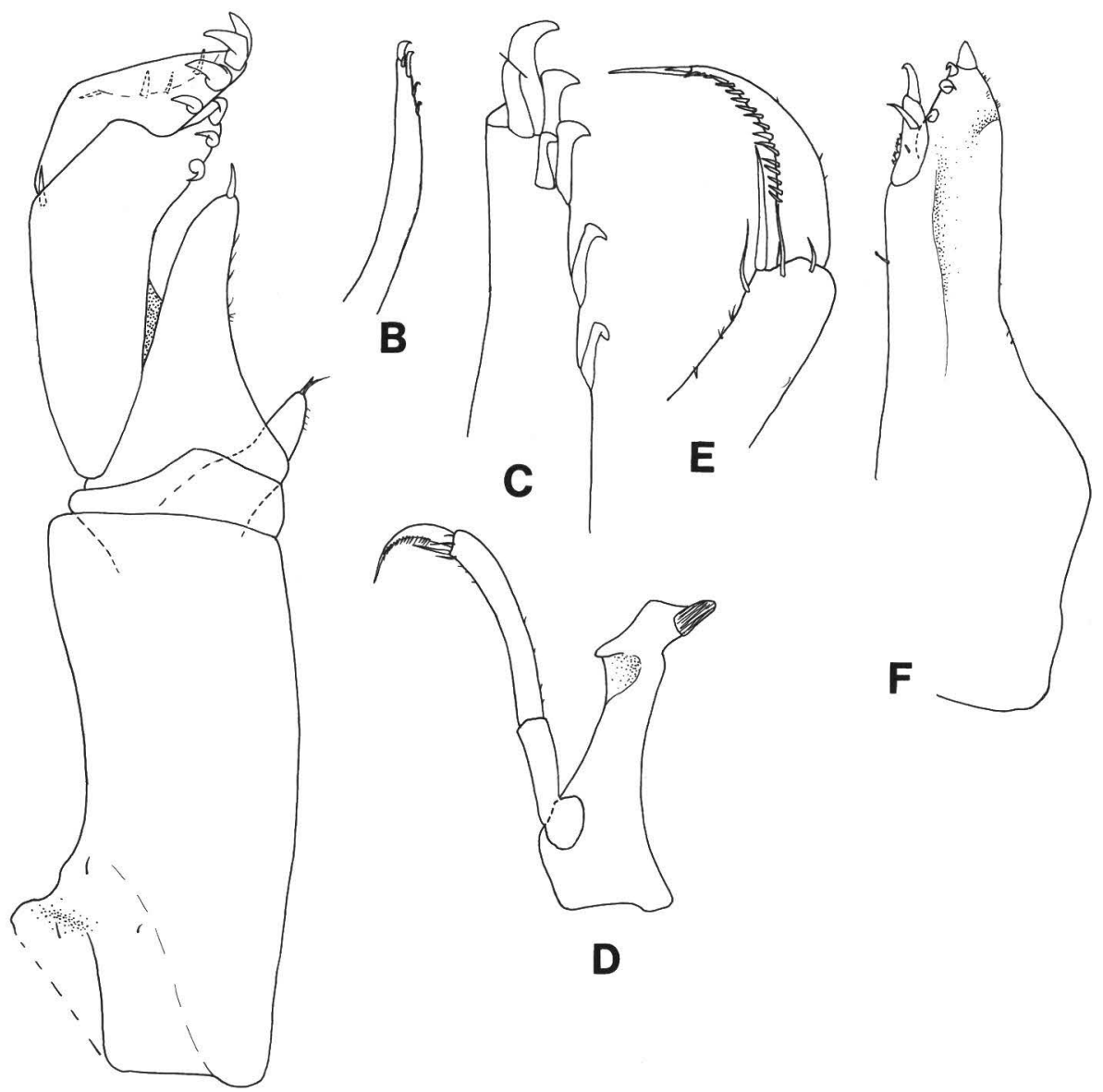

A

Fig. 2. Aega komai sp. nov., holotype. A, maxilliped; B, maxilla; C, maxilla apex; D, mandible; E, mandible palp, terminal article; $F$, maxillule.

$1>2=3<4<5=6>7$; posteroventral angle of pereonite 1 and of coxae 2 and 3 each with acute process, coxae of pereonites 3-6 posteriorly rounded, each with distinct ventral ridge; coxae of pereonite 7 posteriorly subacute with an oblique ridge. Pleon about $20 \% \mathrm{BL}$, pleonite 1 largely concealed by pereonite 7 , posterolateral angles of pleonites 1-4 acute; pleonite 5 partially overlapped by 4 in lateral view. Pleotelson about $15 \% \mathrm{BL}, 0.76$ as long as greatest width, posterior margin subtruncate, deeply serrated with 6-7 marginal serrations on either side of me- dian point; provided with short PMS on lateral margin of each serration, without spines; posteriorly with indistinct and incomplete longitudinal ridge.

Antennule peduncle articles 1 and 2 subequal in total length; article 1 slightly wider (0.9) than long, posterior margin with 2 posterodistal setae; article 2 as wide as long, with prominent anterior lobe, anterior margin 3 times as long as posterior margin; article 30.57 as long as articles 1 or 2, 2.5 times as long as wide; flagellum 0.23 as long as peduncle, with 5 articles, article 1 of which is longest, 
about 2.4 times longer than article 2, extending to anterior of eye. Antenna peduncle articles 1-3 short; article 4 about 0.77 as long as combined lengths of articles $1-3$, posteriorly deeply grooved, with cluster of simple setae at anterodistal angle; article 5 longest, more than twice (2.3) as long as article 4, 1.7 times as long as wide; flagellum slightly longer than peduncular article 5, composed of 10 articles, extending to pereonite 2 .

Frontal lamina anteriorly rounded, about 0.8 times as wide as long, lateral margins converging posteriorly, ventral surface weakly concave. Mandible incisor simple, bluntly rounded; molar process not apparent; palp article 2 longest, 1.6 time as long as article 1, 2.9 times as long as article 3; article 2 with 1 long seta at distolateral margin and 3 shorter submarginal setae; article 3 with 18 stout marginal setae, terminal seta being longest. Maxillule without apparent medial lobe, lateral lobe with 8 flat falcate spines on medial and distal margin. Maxilla lateral lobe with 3 hooked and 1 simple distal spine, lateral lobe 2 weakly hooked spines. Maxilliped palp articles 2 and 3 with distinct distomedial lobes, article 2 with single simple spine at distal end, article 3 with 3 recurved spines, article 4 with 4 large recurved spines, and article 5 short and wide, with 4 simple spines; endite extending beyond palp article 2 , with 2 short simple terminal setae.

Pereopods $1-3$ robust, $5-7$ moderately elongate, pereopod 4 intermediate between both sets. Pereopod 1 basis 1.6 times as wide as long, anterior margin with 4 palmate setae and small simple setae; ischium less than half (0.44) as long as basis; merus short, 1.4 times as wide as long, anterodistal angle with 2 simple spines, posterior margin thickened, weakly lobate; carpus short half as long as propodus; propodus robust 1.7 times as long as wide, palm unornamented, with 3 short simple setae; dactylus robust, strongly and abruptly recurved, about as long as propodus. Pereopod 2 similar to pereopod 1 but slightly less robust; basis twice as long as wide; ischium with 2 spines and single seta at posterodistal angle, single spine at anterodistal angle; merus with 1 spine and 1 short seta at anterodistal angle, posterior margin with 3 spines half way along its length, further 3 and single seta at distal angle; carpus slightly longer than merus, 0.7 times as long as propodus, posterior margin concave, posterodistal angle with single spine and single seta; propodus with palm straight, somewhat produced distally, with 2 prominent simple setae; dactylus weakly curved, subequal in length to propodus. Pereopod 3 similar to pereopod 2 but less robust, differing in having more spines on ischium, and slightly longer spines, and in having a massive blunt spine, slightly less $(0.48)$ than half as long as propodus, slightly more $(0.58)$ than half as long as dactylus, opposing slender and weakly curved dactylus. Pereopod 6 basis 2.6 times as long as wide, posterodistal angle with 2 short spines, anterior margin with 9 palmate setae; ischium 0.7 times as long as basis, 2.4 times as long as wide, posterior margin with 3 clusters of 1, 4 and 4 spines, distal margin with 6 spines anteriorly and about 10 posteriorly; merus 0.6 times as long as ischium, about twice (2.1) as long as wide, posterior margin with 3 clusters of 2,4 and 5 spines, distal margin 5 spines anteriorly and 6 posteriorly the longest of which extends more than half length of carpus; carpus 1.1 times as long as ischium, about 3 times as long as wide, posterior margin with 3 clusters of 1,3 and 1 spines, distal margin 3 spines anteriorly and 5 posteriorly; propodus 1.2 times as long as ischium, about 6.4 times as long as wide, posterior margin with 2 clusters of 1 and 2 spines respectively, anterodistal angle with 1 small spine and 2 palmate sensory setae, posterodistal angle with 3 spines; dactylus 0.4 times as long as propodus, slender. Pereopod 7 similar to 6, but more 

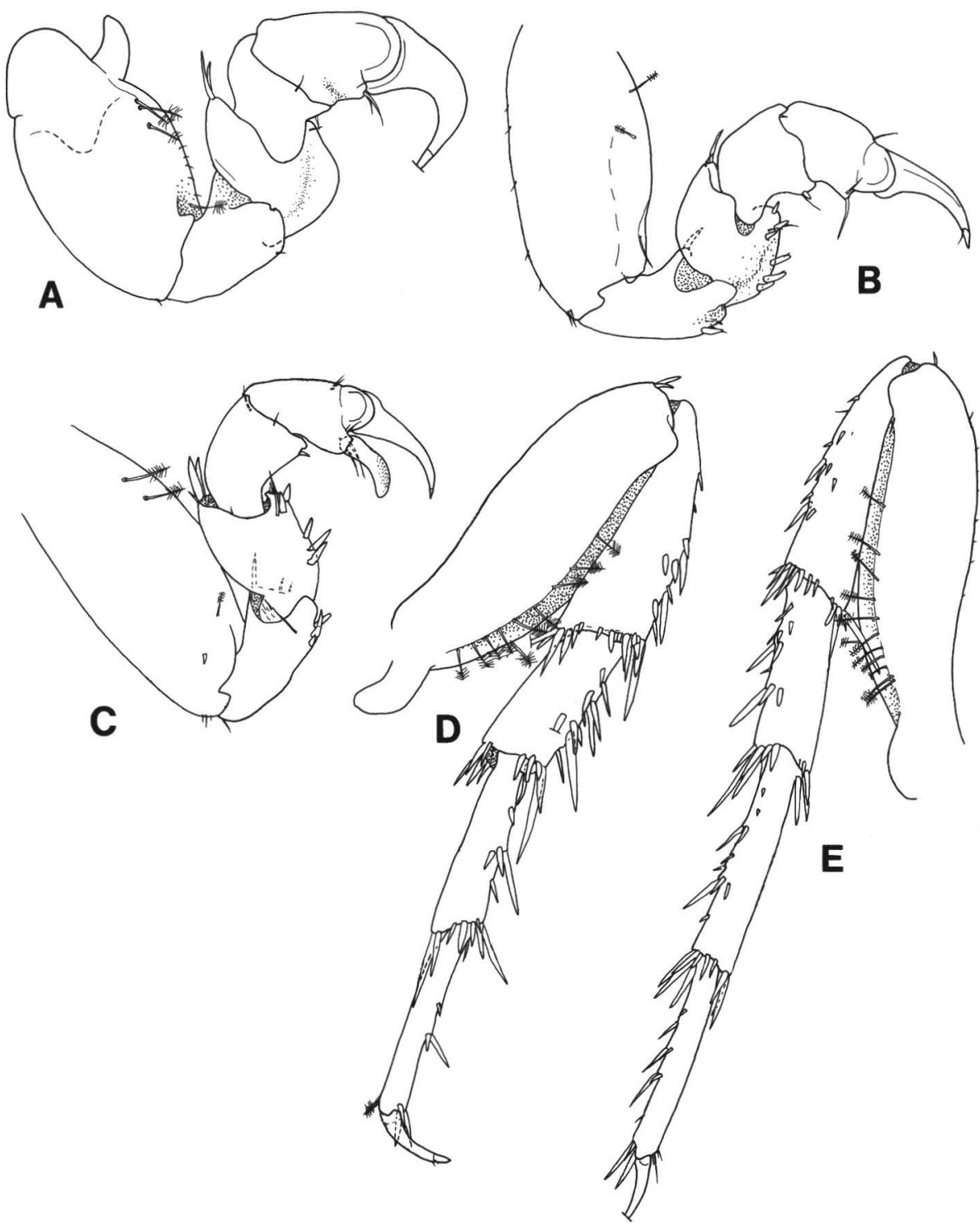

Fig. 3. Aega komai sp. nov., holotype. A-E, pereopods 1-3, 6 and 7 respectively.

slender and more spinose; basis 3.3 times as long as wide, posterodistal angle with 1 short spine, anterior margin with 11 palmate setae; ischium 0.7 times as long as basis, 3.0 times as long as wide, posterior margin 3 clusters of 1,3 and 3 spines, and further 3 submarginal spines, distal margin with 5 spines anteriorly and about 10 posteriorly; merus 0.7 times as long as is- chium, 2.6 times as long as wide, posterior margin with 3 poorly defined clusters of 3 , 4 and 4 spines, distal margin 6 spines anteriorly and 7 posteriorly; carpus 1.3 times as long as ischium, about 5 times as long as wide, posterior margin with 2 clusters of 2 and 3 spines and additional 5 marginal and submarginal spines, distal margin with 4 spines anteriorly and 7 
posteriorly; propodus 0.9 times as long as ischium, about 6.8 times as long as wide, posterior margin with 3 clusters of 2,2 and 2 spines, anterodistal angle with several small setae, posterodistal angle with 3 spines; dactylus about 0.3 times as long as propodus, slender.

Penial processes absent, the vasa deferentia opening flush on surface of sternite 7.

Pleopod 1 exopod 1.7 times as long as wide, slightly shorter (0.94) than endopod, distally sub-acute, lateral margin weakly convex, medial margin strongly convex, ventral exposed surface with scattered cuticular setules, with $\sim 60$ PMS on distal half of ramus; endopod twice as long as wide, distally rounded, lateral margin sinuate, medial margin straight, with 55 PMS on distal two thirds of ramus; peduncle 1.5 times as wide as long, medial margin with 8 coupling hooks, lateral margin without distinct lobe. Pleopod 21.3 times as long as pleopod 1, exopod and endopod with $\sim 110$ and 70 PMS respectively; appendix masculina straight, 0.6 times as long as endopod, apex bluntly rounded, proximal half of lateral margin with small scales; peduncle medial margin with 7 coupling hooks and distally with $\sim 10$ PS, lateral margin with distinct small lobe, without PS. Pleopods 3-5 endopods each with about $\sim 134, \sim 110$ and 116 PMS respectively, each with distal point, each with transverse suture incomplete, each with lateral margin more strongly convex than medial margin; peduncle medial margins with 7,5 and 0 coupling hooks and 11, 8 and 0 PS respectively, lateral margins distinctly lobate with submarginal row of PS. Pleopods 3-5 exopods with 20,14 and 0 PMS respectively, setae being on distal margin only; each with medial margin straight, lateral margin convex with sub-basal and distolateral small triangular process. Uropod with both rami subequal in length, extending clearly beyond posterior margin of pleotelson; exopod about 4.3 times as long as proximal width, lateral margin with 5 large teeth, and apical point, medial margin with 1 large tooth; endopod lateral margin convex, indistinctly and deeply serrate with 3 large and 4-5 small teeth, bifurcate apical point, medial margin 1 or 2 large and 1 small teeth, continuous short PMS present on non-serrate margins and on lateral margins of teeth.

Remarks. - Several characters serve to immediately distinguish Aega komai sp. nov., from all other members of the genus. These are the plate-like expansion of antennule articles 1 and 2, the flattened and expanded antenna article 5, the short, truncate and deeply serrate pleotelson, together with the deeply serrate uropods, and the presence of conspicuously large spine of pereopod 3 only. There are two other species that are obviously closely allied to Aega komai, sharing the same general appearance, and most of the characters mentioned above. These two species are Aega dofleini Thielemann, 1910, and Aega angustata Whitelegge, 1901. Both of these species lack the truncate posterior margin to the pleotelson, as has been clearly illustrated by Thielemann (1910) and Hale (1925), and furthermore the uropod exopod is far more weakly serrated than in Aega komai. In Aega angustata (Australian specimen, see material examined) pereopods 6 and 7 are more slender, the width to length ratios for the species being in $A$. angustata for pereopod 6 carpus 1: 5.3, propodus 1: 11.3 , for pereopod 7 carpus 1 : 6.7, propodus 1: 11.6. The figures for $A$. komai are pereopod 6 carpus 1: 3.0, propodus 1: 6.4 , for pereopod 7 carpus 1: 5.0 , propodus 1: 6.8 .

Stephenson (1980) recorded Aega angustata Whitelegge, 1901 from New Zealand, but did not give detailed figures. The dorsal and ventral views of the ani- 

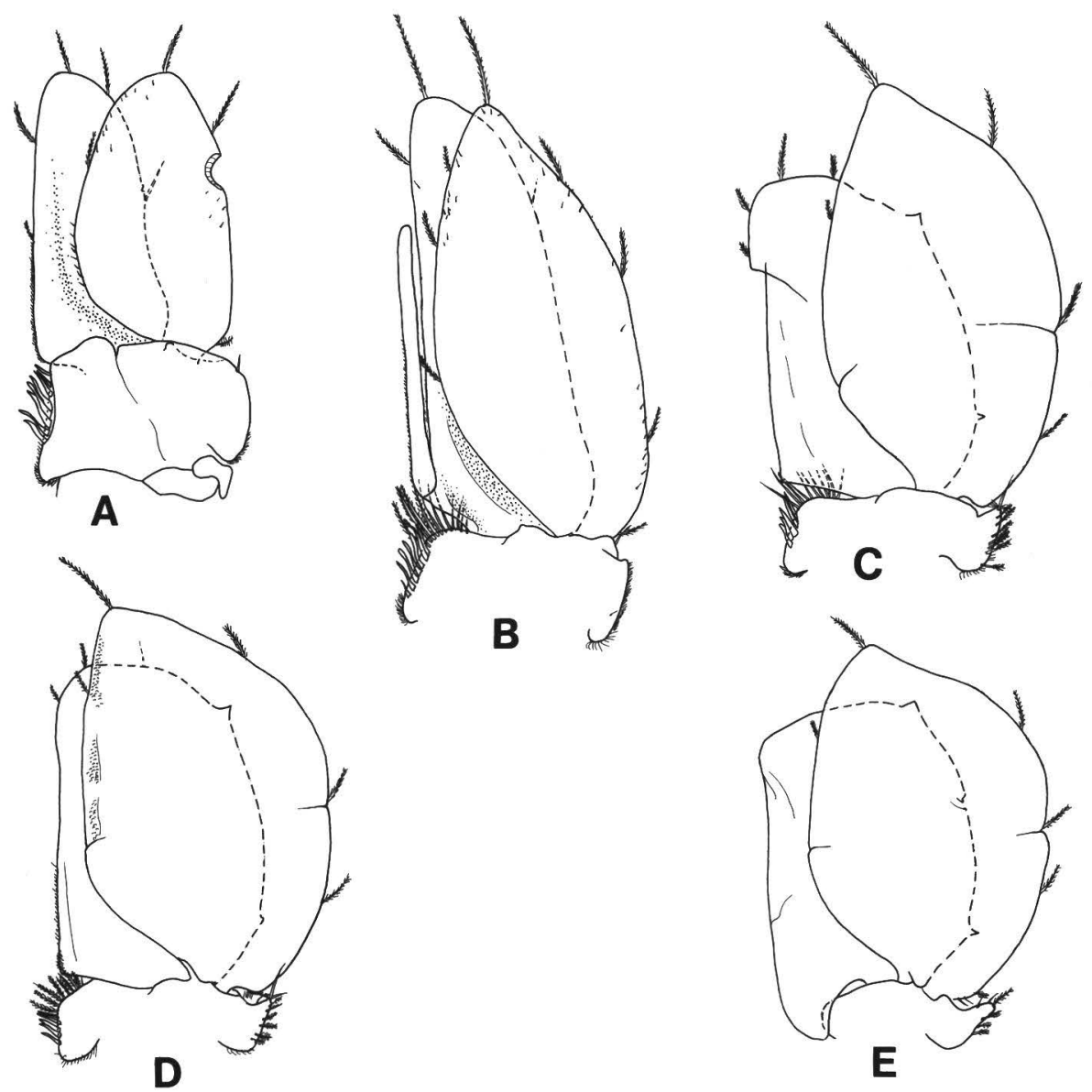

Fig. 4. Aega komai sp. nov., holotype. A-E, pleopods 1-5 respectively.

mal were illustrated by indistinct halftone photographs, which do not clearly show the posterior of the pleotelson and the uropods, and it appears possible that these specimens may in fact be Aega komai. Currently, while it is easy to distinguish Aega angustata Whitelegge, 1901 and Aega dofleini from Aega komai, it is not easy to distinguish those two inadequately described species from each other.

The presence of a distinctive and very large spine on the dactylus of pereopod 3 is not unique to this group of species. As discussed by Barnard (1960), it is present in Aega chelipous Barnard, 1960 and in at least three other species: Aega concinna Hale, 1940, Aega crenulata Lütken, 1859 and Aega webbi (Guérin, 1836). In these last three species, pereopod 2 also has an enlarged propodal spine. All of these four species, while possessing flattened antennule peduncles, are otherwise rather dissimilar to the Aega komai - Aega angustata species in lacking the deeply serrate pleotelson and uropods. Until such time as many more species of Aega are fully described, it is not possible to speculate about possible relationships within the genus. 


\section{Acknowledgments}

I thank Dr. Tomoyuki Komai (Chiba Natural History Museum, Japan) for the opportunity to examine this specimen. I also thank Mr. Kim Larsen (Zoologisk Museum) for his inking of the original drawings, and Dr. Penny Berents (Australian Museum, Sydney) is for the loan of specimens.

\section{Literature Cited}

Barnard, K. H., 1960. Isopoda parasitic on Madagascar fish. O.R.S.T.O.M., Institute Scientifique de Madagascar, Memoires, série F, 3: 93-95.

Brusca, R. C., 1983. A monograph on the isopod family Aegidae in the tropical eastern Pacific. 1. The genus Aega. Allan Hancock Monographs in Marine Biology, 12: 1-39.

Guérin, M. F. E., 1836. Crustacés. In: Expedition Scientifique de Moree, section des Sciences physiques. III, $1^{\mathrm{er}}$ parte, Zoologie, deuxième section. Des animaux articulés. 1832, pp. 30-35. Atlas Zool., 1835.

Hale, H. M., 1940. Report on the cymothoid Isopoda obtained by the F.I.S. "Endeavour" on the coasts of Queensland, New South Wales, Victoria, Tasmania, and South Australia. Transactions of the Royal Society of South Australia, 64: 288-304, pl. XVIII.

Kensley, B., \& Schotte, M., 1989. Guide to the Marine Isopod Crustaceans of the Caribbean. Smithsonian Institution Press, Washington, D.C., 308 pp.

Kussakin, O. G., 1979. Marine and brackishwater Isopoda of cold and temperate waters of the Northern Hemisphere. Flabellifera. Akademy of Science, USSR, Leningrad, pp. 470.

Lütken, C. F., 1859. Nogle bemærkninger om det nordiske Aega-arter samt om Aegaslægtens rette begrændsning. Videnskabelige Meddelelser fra den Naturhistorisker Forening i København: 65-78.

Nunomura, N., 1981a. Isopod crustaceans in
Sado Island, the Sea of Japan. Annual Report of the Sado Marine Biological Station, Niigata University, 11: 43-62.

, 1981b. Three species of flabelliferan isopods (Crustacea from the East China Sea, including the description of a new species of Syscenus. Bulletin of the Toyama Science Museum, 12: 13-18.

, 1988. A new species of the genus Aega (Crustacea Isopoda) from the Sea off Okinawa. Bulletin of the Toyama Science Museum, 12: 19-22.

_ 1993. A new species of the genus Aega from Toyama Bay. Bulletin of the Toyama Science Museum, 16: 11-14.

Richardson, H. R., 1898. Description of four new species of Rocinela, with a synopsis of the genus. Proceedings of the American Philosophical Society, 37: 8-17.

-1904 . Contributions to the natural history of the Isopoda. Proceedings of the United States National Museum, 27: 1-89. $\longrightarrow, 1909$. Isopods collected in the northwest Pacific by the U.S. Bureau of Fisheries Steamer "Albatross" in 1906. Proceedings of the United States National Museum, 37: 75-129.

Stephenson, A. B., 1980. Aega angustata Whitelegge, 1901 (Isopoda: Aegidae), a new record from New Zealand waters. Records of the Auckland Institute and Museum, 17: 153-155.

Thielemann, M., 1910. Beiträge zur Kenntnis der Isopodenfauna Ostasiens. Beiträge zur Naturgeschichte Ostasiens. Abhandlungen der Mathematisch-Physkalischen Klasse der Koeniglich Bayerisch Akademie der Wissenschaftliche, 2, suppl.-bund 3: 1-110.

Whitelegge, T., 1901. Crustacea. Part 2. Isopoda, Part 1. Scientific results of the trawling expeditions of the H.M.C.S. "Thetis". Memoirs of the Australian Museum, 4: 201-246.

Address: Zoologisk Museum, Universitetsparken 15, Copenhagen $\varnothing$, DK 2100, Denmark. E-mail: nlbruce@zmuc.ku.dk 